\section{A NEW THERMOGRAPH ${ }^{1}$}

THE instrument under consideration is a thermograph for recording the atmospheric temperature, the fluctuations of which are much less regular and more frequent than one who has not made a study of it would suppose. It records the temperature directly from the column of mercury in the tube of a thermometer by dots or perforations upon a sheet of paper previonsly ruled with degrees and hours.

Its principal parts are, as shown in Fig. I of plate :

I. A thermometer in the form of an ordinary mercury thermometer, but open at the top of the tube, and having a wire entering the bulb and connected to one pole of a battery, the other pole of which is connected to the mechanism of the instrument.

2. An upright cylinder revolving by clockwork, covered with a paper which is divided vertically into twenty-four parts by lines representing the hours, and horizontally by lines representing the degrees.

3. A bar raised and lowered by mechanism driven by clockwork, furnished below with a needle entering the tube of the thermometer, and carrying a pencil-or preferably a pointdriven forward by a small electro-magnet when the circuit is closed by the needle entering the mercury, and then making a mark at the proper place upon the paper and indicating the temperature.

The bar carrying the needle rises about half an inch from the point at which the needle leaves the mercury, and then descends until the reedle again touches the mercury, whether that in the meantime shall have risen or fallen, when the point makes its mark upon the paper and the bar again commences to rise.

This movement is accomplished by the mechanism shown in the drawing, of which only the wheel $\mathrm{E}$, gearing into the rack upon the needle-bar, is shown in Fig. $r$, but which is show $n$ in full and up on an enlarged scale in Fig. 2, which is a top view. The two wheels A and B are moved by clockwork (not shown), and are constantly revolving in oppusite directions, as indicated by the arrows. These wheels are not attached to the shaft $u_{i}$ on which the wheel $\mathrm{E}$ is fixed, but are attached to sleeves which move without affecting that wheel except when they are joined to it by the clutches $C$ or $D$. They are so geared that when the wheel $\mathrm{E}$ is joined to them, its rim moves at the rate of half an inch per minute. Upon the shaft wi!h the wheel $\mathrm{F}$ is also a loose sleeve $\mathrm{F}$, which is free when the clutch $\mathrm{C}$ is not in action, but which moves with that wheel when that clutch is on.

The levers actuating the two clutches unite and move upon a common pivot, from which point they extend as an arm, which is capable of a lateral moverneut between two stops, bringing one or the other of the clutches into action.

Opposite to the wheel $\mathrm{E}$, the needle-har passes through a guide, which is furnished on the back with a small wheel taking the thrust of the gear and reducing friction. For a lower guide, the needle-bar is furnished on each side with a rod parallel to the needle, and of nearly the same length. These rods are at such distance apart that they pass clear of the thermometer tube. They are not shown in the drawing, as they would lie directly in front of and behind the needle and tube

The teeth of the clutches are partly $\mathrm{V}$-shaped and partly square, or nearly so, as shown in Fig. 3 ; that is, they have sligltly tapered sides but $V$-shaped points and bases, so that they enter freely, as entirely V-shaped teeth would do, and when in action they have no outward thrust. The V-shaped base strengthens the tooth and admits the point of the opposite tooth.

A very small spring on each side of the sleeve $F$ holds it out of gear while the clutch $\mathrm{C}$ is off.

Beneath the clutch arm is a pressure spring, one end of which presses against the end of the arm, and the other against a plate moving upon the same pivot with the arm, which plate also is capable of a lateral movement between its stops.

If this spring-plate is moved in either direction to its stop, carrying with it the base of the spring, the clutch-arm will be moved in the other direction, and the clutch on that side will be brcught into action; and if the position of the spring-plate with the base of the sfring be reversed, the position of the clutcharm will be reversed-that clutch will be disengaged, and the other one will be engaged-the wheel $\mathrm{E}$ being moved, and the needle-bar raised or lowered accordingly.

To the sleeve $\mathrm{F}$ is attached an arm which is connected by a draft-rod to the spring-plate.

I A paper by G. Morgan Eldridge, read at the stated meeting of the Franklin Institu e. A pril:6, $18 \varepsilon_{2}$. Coniributed by the Autho:
When the clutch $\mathrm{C}$ is in action-as shown in the drawingconnecting the wheel $\mathrm{A}$ with the wheel $\mathrm{E}$ and the sleeve $\mathrm{F}$, raising the needle-bar, the arm of the sleeve $F$ draws upon the springplate-moving to that side the base of the reversing-spring, which, when its base has pas ed the line between the pivot and the end of the clutch-arm, presses that arm to the other side, disengaging that clutch, loosing the sleeve $F$, engaging the other clutch, and reversing the motion of the needle-bar, which now descends.

The length of the arm on the sleeve $F$ is such that when the needle-bar bas risen half an inch the spring-plate is moved over, and the clutch-action is reversed.

When, by descending, the needle is brought in contact with the mercury and a circuit is made, the large electro-magnet, thus vitalised, attracts its armature, which is attached to a lever con

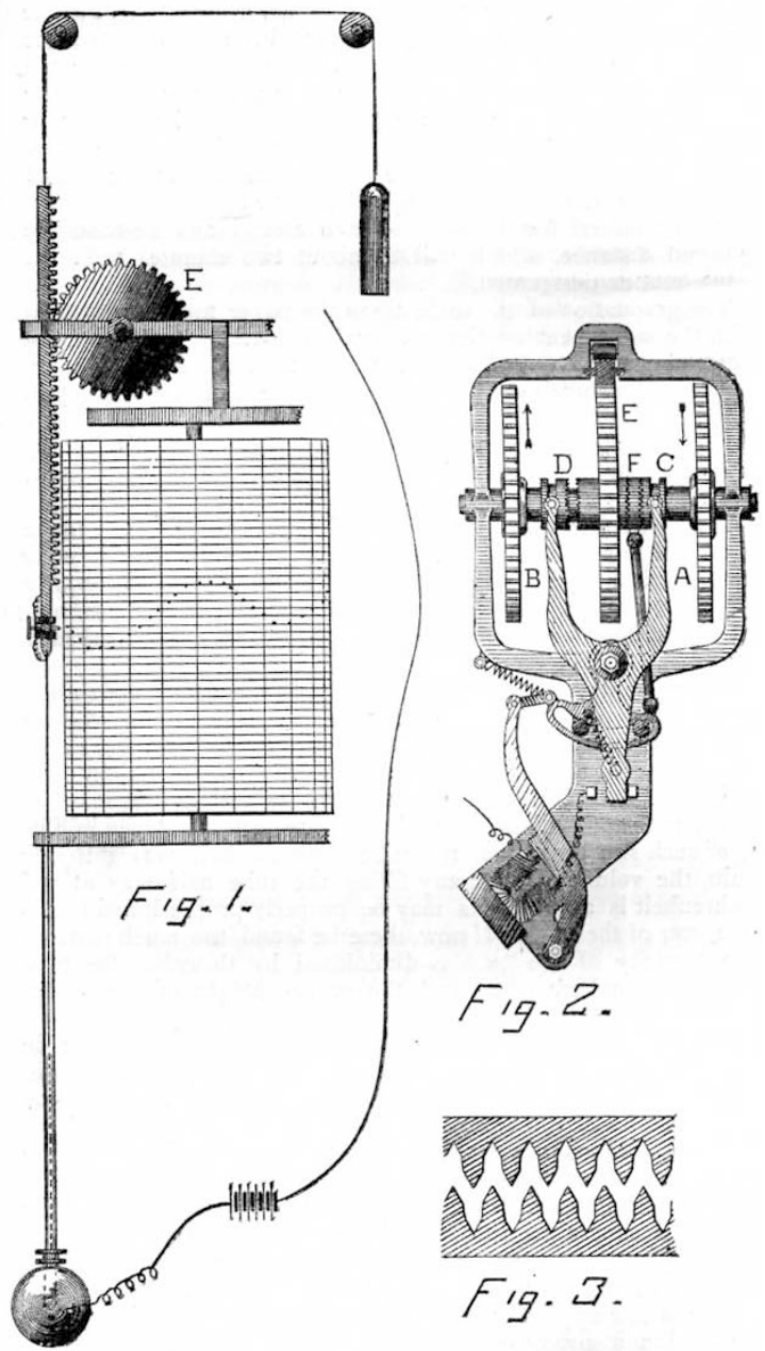

nected with and drawing upon the spring-plate, and moves the base of the reversing spring to that side, changing the position of the clutch-arm, and reversing the action of the clutches and the movement of the needle-bar, while at the same time the recording-point upon the needle bar is, by its electro-magnet, driven into the paper, and the temperature is recorded upon the scale.

The sleeve $F$, being loose, yields to the movement of the spring-plate, and is afterwards held by its clutch, and acts as before.

The action of the large electro-magnet is supplemented by that of a spring drawing upon the same side of the spring. plate, whose strength is such that it is not quite sufficient of itself to overcome the thrust of the reversing spring, but whose force is greatest when that of the electro-magnet, by reason of 
its distance from its armature, is least, the greatest possible portion of the work being thus put upon the clockwork, and the least upon the battery.

This spring aids the electro-magnet, but does not in anywise reduce the effect of the reversing spring in holding the clutch to its work; so long as the base of that spring is unmoved, its action is unimpaired. The resistance of these springs occurs only during the ascent of the needle-bar, which is, therefore, counterpoised to excess, and the resistance and the motion are thus rendered uniform. By reason of the form of the clutch-teeth before described, there is no outward thrust upon the clutches while in action, and bence the reversing spring requires only to be strong enough to throw the arm over and to shift the clutches. The stop of the clutch-arm next the electro-magnet is an insulated plate, to which the battery-wire leading from the magnet is connected, so that as soon as the arm has left the stop the circuit is again broken, although the needle may for a short time remain in contact with the mercury; the recording-point is at once withdrawn, and thus makes upon the paper a single perforation which must be a true record of the position of the mercury in the tube, uuaffected by friction or other disturbing cause, since this action must always take place at the moment of contact of the needle with the mercury, and these dots or perforations are repeated at the end of each interval of time required for the needle-bar to ascend and descend the required distance, which will be about two minutes with the wheel-motion designated.

The graduation of the scale upon the paper must correspond with the movement of the mercury in the tube of the thermometer as accurately as the graduation of the scale of an ordinary thermometer corresponds with the movement of the mercury in its tube.

If but one instrument of this sort is to be made this is very easy, the rate of motion is accertained, a scale is made to fit it, and the paper is ruled to that scale.

In all thermometers heretofore made the scale has been made to fit the tube, but if more than one of these instruments is to be made, it becomes necessary, or at lea-t very convenient, to have one set of ruled papers that will fit all the instruments, and it then becomes necessary to reverse the practice and to make the tubes to fit the scale.

The rise and fall of mercury in a thermometer depends upon the proportion between the diameter of the tube and the volume of mercury in the tube and bulb, and while it is possible to construct these parts in such proportion as to obtain proximately a given motion, it is not possible thus to obtain it exactly.

The tube and bulb are made in sefarate parts, as shown in Fig. I, of such size that when the tube is thrust half way into the bulb, the volume of mercury filling the tube half way at $32^{\circ}$ Fahrenheit is as nearly as may be properly proportioned to the diameter of the tube. If now there be found too much motion, the capacity of the bulb is diminished by thrusting the tube further in, and vice versa, and the proper height of mercury at $32^{\circ}$ for that purpose is marked upon the tube.

Mercury exposed to the air will slowly form a coating of oxide upon its surface. To prevent this, a small quantity of glycerin or of oil free from oxygen is placed in the thermometer tube above the mercury. If, notwithstanding, the oxide shall accumulate to an inconvenient extent, the observer in charge of the instrument will remove the thermometer from its place, and will put the bulb in warm water until the oxide is floated off. $\mathrm{He}$ will then supply the loss with pure mercury, determining the proper quantity by inmersing the bulb in broken ice, when the mercury column should stand at the mark for $32^{\circ}$.

The whole apparatus, excent the thermometer itself, can be inclosed, and so protected from the weather and dust, while the thermometer is exposed to the air below.

The system is equally applicable to a barometric record, in which case, on account of the small range of motion, the needle-bar is connected to a lever, thus increasing the range of the record.

\section{SCIENCE IN BOHEMIA I}

THE Bohemian Society of Science continues its useful career, which has already lasted for eighty-four-years, and its latest publications (the Memoirs, the Proceedings, and the annual I "Abhandlungen der Mathematish-Wissenschaftlichen Classe der K. Böhmischen Gesellschaft der Wissenschaften, vom Jahre 1879-1880, vi Folge, Band $x$. (Prag. I 881 ). "Sitzungsberichte" of the same Society,
1879 and for 1880 . "Jahresberichte" of the same, for 1879 and 1880 .
Reports) contain many valuable papers, devoted partly to science in general, but mostly to the exploration of Bohemia itself in its various aspects. The last volume of its Memoirs ("Abhandlungen" for 1879-1880, series vi. vol, x.) contains a series of very interesting papers, each of them being the result of careful and extensive research. Prof. Franz Farsky gives the results of varied experiments which were undertaken at the experimental agricultural station at Tabor, on the growth of food-plants ir water containing solutions of those salts which constitute the ash of the plant. The infuence of alkaline and acid solutions, and especially that of chlorine, which proved to be a most important element of vegetation, were submitted to varied experiments, all the results of which are published in full. The general reader will notice with interest the beautiful results obtained by the culture of oats and barley in glasses of water, which contained the necessary salts, the plant being simply planted in a bit of cotton. Dr. F. I. Studnicka publishes in the same volume the complete tables of observations on the amount of rain in Bohemia during the years 1879 and 1880 , at no Jess than 312 stations in 1879 and at 289 stations in 1880 . If we remember that besides these stations there are very many others established by the Bohemian Foresters' Society, and that the whole number of stations where the amount of rain is accurately measured day by day, amounts to 800 , we can see that Bohemia has probably the widest network of ombrological observations in Europe. We notice that the most rainy places in Bohemia are Maader, Rehberg, and Neuwelt (1744, I572, and I 505 millimetres per year respectively), all these situated at great heights $(985,848$, and 683 metres $)$, whilst the less rainy places are Kapic, Slaten, anâ Kladno (431, 438, and 456 millimetres), situated respectively at altitudes of 322,246 , and 380 metres.

Dr. F. Ullik contributes a paper on the matter suspended and dissolved in the water of the Elbe, at Tetschen. Samples of water were taken three times every day, and the samples of each day were analysed separately with regard to the matter suspended, as well as to the quantity of chlorine, ammonia, nitric acid, and organic substances. Besides, 22 complete analyses of different types of water, and 12 of ooze, were made. The water passing through the Elbe at Tetschen proved to be $9,903,510,660$ cubic metres during the year October 15,1876 , to October I5, 1877), which contained $776,309,959$ kilograms of suspended or dissolved matter. During the year 1877, the amount of water run was $9,456,939,810$ cubic metres, which contained 36,557 metrical tons of $\mathrm{K}^{2} \mathrm{O}, 69,63 \mathrm{I}$ tons of $\mathrm{Na}^{2} \mathrm{O}$, $266,08 \mathrm{I}$ tons of $\mathrm{CaO}, 48,915$ tons of $\mathrm{MgO}, 120,553$ tons of $\mathrm{SO}^{3}, 83,336$ tons of chlorine, 778 tons of ammonia, and II, I96 of nitric acid. As to the sources of these immense quantities of mineral substances, Dr. Ullik points out that the amount which is supplied by waste water of manufactures and sewage is usually over-rated. Thus, if the well-known sulphuric acid manufacture at Aussig would pour all the acid it produces into the Elbe, it would give only 5000 tons of $\mathrm{SO}^{3}$ per year, that is, only the 24 th part of sulphuric acid anhydride contained in the waters of the river. The amount of mineral substance poured into the river by all the breweries of Bohemia would give only 401 tons per year, that is, the 1562 nd part of all the minerals contained in the Elbe water. And, if all mineral substance contained in the sewage from the $5,000,000$ inhabitants of Bohemia would reach the Elbe, it would yield only 33,250 tons, that is, $1-20$ th of what is really contained in the water of the river. Therefore, it is obvious that the chief source of these substances in the riverwater must be sought for in the supply brought in by springs.Dr. Siegmund Giunther contributes to the same volume an interesting notice on the "Algorithmus Linealis," by Meinrich Strömer, which appeared in 1512 , being one of the products of the revival of taste for mathematics which characterises, in Germany, the beginning of the sixteenth century. The same volume contains an elaborate paper on the Christian Calendar and on the methods of improving it, by Dr. W. Matzka; and a notice on the electrical clock of Rebicek, by Dr. A. Walten. hofen. It is worthy of notice that all papers that appear in the Abhandlungen are written in German, and are sold by the Society as separate pamphlets.

The Sitzungsberichte, or Prcceedings, contain such a mass of valuable papers that we can notice only the more important of them. They are especially rich in mathematics, and we find (in the volume for the year I879) papers by Dr. S. Günther, on the application of orthogonal co-ordinates to one problem of the potential theory; on the normals to parabolæ, by Dr. K. 